\title{
Comparison of postoperative complications between segmentectomy and lobectomy by video-assisted thoracic surgery: a multicenter study
}

\author{
Benoit Bédat ${ }^{1 *}$, Etienne Abdelnour-Berchtold ${ }^{2}$, Thomas Perneger ${ }^{3}$, Marc-Joseph Licker ${ }^{4}$, Alexandra Stefani ${ }^{1}$, \\ Matthieu Krull', Jean Yannis Perentes ${ }^{2}$, Thorsten Krueger ${ }^{2}$, Frédéric Triponez ${ }^{1}$, Wolfram Karenovics ${ }^{1}$ and \\ Michel Gonzalez ${ }^{2}$
}

\begin{abstract}
Background: Compared to lobectomy by video-assisted thoracic surgery (VATS), segmentectomy by VATS has a potential higher risk of postoperative atelectasis and air leakage. We compared postoperative complications between these two procedures, and analyzed their risk factors.

Methods: We reviewed the records of all patients who underwent anatomical pulmonary resections by VATS from January 2014 to March 2018 in two Swiss university hospitals. All complications were reported. A logistic regression model was used to compare the risks of complications for the two interventions. Adjustment for patient characteristics was performed using a propensity score, and by including risk factors separately.

Results: Among 690 patients reviewed, the major indication for lung resection was primary lung cancer (86.4\%) followed by metastasis resection (5.8\%), benign lesion (3.9\%), infection (3.2\%) and emphysema (0.7\%). Postoperatively, there were 80 instances (33.3\%) of complications in 240 segmentectomies, and 171 instances (38.0\%) of complications in 450 lobectomies $(P=0.73)$. After adjustment for the patient's propensity to be treated by segmentectomy rather than lobectomy, the risks of a complication remained comparable for the two techniques (odds ratio for segmentectomy $0.91(0.61-1.30), p=0.59)$. Length of hospital stay and drainage duration were shorter after segmentectomy. On multivariate analysis, an American Society of Anesthesiologists score above 2 and a forced expiratory volume in one second below $80 \%$ of predicted value were significantly associated with the occurrence of complications.
\end{abstract}

Conclusions: The rate of complications and their grade were similar between segmentectomy and lobectomy by VATS. Keywords: Complication, Segmentectomy, Lobectomy, Video-assisted thoracic surgery

\section{Background}

Currently, pulmonary lobectomy is routinely performed by video-assisted thoracic surgery (VATS) for several indications. In patients with lung cancer, VATS lobectomy is considered safe and effective in early stage non-small cell lung cancer (NSCLC) [1-3]. Furthermore, compared to open lobectomy, the VATS approach is associated with less postoperative pain and better quality of life [4].

\footnotetext{
* Correspondence: benoit.bedat@hcuge.ch

${ }^{1}$ Division of Thoracic and Endocrine Surgery, University Hospitals of Geneva,

Geneva, Switzerland

Full list of author information is available at the end of the article
}

In parallel, VATS segmentectomy is increasingly proposed as an alternative to lobectomy to spare pulmonary parenchyma for benign and malignant lesions. In patients with NSCLC, segmentectomy seems to ensure equivalent oncological outcomes for tumor sizes smaller than $2 \mathrm{~cm}$ without nodal involvement $[5,6]$.

Evidence of functional benefit of segmentectomy over lobectomy remains low with debatable results, but the former seems to better preserve lung function via an increased function of the ipsilateral non-operated lobe $[7,8]$. However, the segmentectomy procedure requires more extensive and deeper dissection into the hilum and

(C) The Author(s). 2019 Open Access This article is distributed under the terms of the Creative Commons Attribution 4.0 International License (http://creativecommons.org/licenses/by/4.0/), which permits unrestricted use, distribution, and 
division of the intersegmental plane, which may lead to an higher rate of prolonged air leaks [9]. Furthermore, the use of staplers to divide the intersegmental plane can induce compression of the adjacent lung and may cause atelectasis and pneumonia of the remnant lobe. Few studies that reported incidence and severity of postoperative complications following segmentectomy and lobectomy by VATS, and other retrospective studies that have yielded contradictory results and had study limitations (e.g., small sample or single-center cohort; incomplete data about complications; analysis of patients with earlystage cancer; lack of analysis of predictive factors for complications) [9-13].

The aim of this study was to compare the incidence of post-operative complications between VATS segmentectomy and VATS lobectomy and to identify their predictive factors.

\section{Methods}

\section{Patients}

We reviewed the records of all patients who underwent anatomical pulmonary resections by VATS from January 2014 to March 2018 at the University Hospitals of Lausanne and Geneva in Switzerland. The local ethics committee approved this study (referral number: 201800179) and waived the need to obtain informed patient consent. All indications were included. All patients with NSCLC were presented at an interdisciplinary tumour board. The indication for VATS lobectomy for lung cancer was proposed in patients with tumors resectable by a minimally invasive approach. The indication for VATS segmentectomy for lung cancer was proposed in patients with a nodule smaller than $2 \mathrm{~cm}$ without nodal involvement. VATS segmentectomy have been performed "intentionally", unrelated to the fitness of the patient.

\section{Surgical technique}

Four surgeons who had each performed $>100$ cases of VATS lobectomy included in this study carried out all segmentectomies. Surgical resections were undertaken using an anterior three-port approach. All vascular structures were transected using endoscopic staplers or an energy device and complete dissection of hilar and mediastinal lymph nodes was carried out in patients with NSCLC. All bronchial structures were transected using endoscopic staplers. In segmentectomy, the intersegmental plane was divided using staplers. In lobectomy, a fissure-less technique was performed preferentially.

\section{Classification of postoperative complications}

Patient records were extracted from the hospital data management system. The following data were obtained: patient demographics and comorbidities; preoperative lung function; indication for surgery; type of pulmonary resection; duration of surgery; histologic findings; duration of drainage; length of hospital stay (LOS); postoperative complications and mortality.

The primary endpoint was the occurrence of the following cardiopulmonary complications: atrial fibrillation; acute myocardial ischemia; pneumothorax; hemothorax; prolonged air leak (PAL), defined as an air leak lasting beyond postoperative day 7; acute respiratory distress syndrome (ARDS), defined using the Berlin classification [14]; pneumonia, defined by the need for antibiotics according to the appearance of new lung infiltrate at chest- $\mathrm{X}$ rays, fever, or an elevated white blood cell count $>12,000$ per $\mathrm{ml}$; acute pulmonary edema; massive subcutaneous emphysema; atelectasis; pulmonary embolism; chylothorax; cardiac infarction; empyema; bronchopulmonary fistula.

The secondary endpoint was the occurrence of any other complication, such as recurrent and phrenic nerve injury, gastrointestinal ileus, colitis, gastroparesis, upper gastrointestinal bleeding, septic shock and acute renal failure.

The complications were then classified in 3 groups according to the Thoracic Morbidity and Mortality system: [15] Minor complications (grade I and II), major complications (grade III and IV) and mortality (grade V). For patients experiencing more than one complication, the most severe grade was assigned.

\section{Statistical analysis}

For patient characteristics, chi-squared or Fischer's exact tests were used to analyze categorical variables. A T-test or Mann-Whitney U test was used to analyze continuous variables.

Since patients were assigned to lobectomy or segmentectomy based on their clinical characteristics (and not at random), the comparison of complication rates required adjustment for potential confounders. A propensity score was calculated from a logistic regression model, including following variables: gender, the presence of chronic obstructive pulmonary disease (COPD), indication for surgery (primary lung cancer, metastasis, benign lesion, emphysema, infection), and location of the lesion (lobe). This model represented the probability of being assigned to VATS segmentectomy as opposed to VATS lobectomy. A Nagelkerke $R$ [2] test was used to measure the goodness-of-fit and the area under the curve was used to measure propensity-score performance. A logistic regression analysis was used with the propensity-score model and the type of intervention to assess the occurrence of complications. We compared the distributions of propensity scores in patients treated with segmentectomy and lobectomy, and excluded tail distributions that received only one treatment modality (49 patients with propensity $<0.10$ were all treated with lobectomy, and 6 patients with 
propensity $>0.85$ were all treated with segmentectomy). We then obtained a classic logistic regression model where the occurrence of any complication was a function of treatment modality and of the continuous propensity score (Model 1). To verify the robustness of the result we also performed a conditional logistic regression analysis, using 15 matched sets of patients (propensity 0.100-0.149, $0.150-0.199,0.200-0.249$, etc) (Model 2). These analyses were repeated for cardio-pulmonary complications only.

For the occurrence of any complication, the predictive factors for complications were also analyzed using a multivariate logistic regression models. The cutoffs of the forced expiratory volume in one second (FEV1) and the diffusing capacity of the lungs for carbon monoxide (DLCO) predictive values were chosen according to established recommendations [16].

\section{Results}

\section{Patients and surgery}

Patients' demographic and clinical characteristics are summarized in Table 1. Overall, 690 patients were reviewed, including 240 who had VATS segmentectomies and 450 who had VATS lobectomies. The conversion rate to thoracotomy was $5.8 \%$ for both procedures. Most interventions were performed in center 1 (62.6\%). As shown in Table 1, preoperative patient characteristics were not significatively different regardless the type of surgery for age, comorbidities and American Society of Anesthesiologists (ASA) score. The major indication for lung resection was primary lung cancer (86.4\%) followed by metastasis resection (5.8\%), benign lesion (3.9\%), infection (3.2\%) and emphysema (0.7\%). The type of surgery differed among indications (Table 1). Patients with primary lung cancer were more likely to have VATS lobectomy than VATS segmentectomy (91.1\% versus $77.5 \%$, respectively). On the other hand, resection of metastasis and benign lesions was likely performed by VATS segmentectomy. The location of the lung resection differed significantly between the procedures, with an upper right location predominantly found in the lobectomy group and a left location in the segmentectomy group. Overall, a systematic lymph node dissection was significantly more often performed during VATS lobectomy (Table 1). The FEV1 and DLCO did not differ between procedures.

As shown in Table 2, in patients with primary lung cancer, larger tumor and nodal involvement were strongly associated with VATS lobectomy. The duration of operation and the rate of conversion to thoracotomy were similar between both groups.

\section{Complications}

As shown in Table 2, overall, 33.3\% of patients experienced postoperative complications after VATS segmentectomies and 38\% after VATS lobectomies. Most patients had only one complication and the average number of complications per patient was not significantly different between segmentectomy and lobectomy. The reoperation rate was not significantly different for the two procedures. VATS sleeve lobectomy was performed in 14 patients, $50 \%$ of whom had cardiopulmonary complications. Upper bilobectomy was performed in 11 patients, 54\% of whom had cardiopulmonary complications. According to the TMM system, the grade of complications was comparable between both procedures (Table 2). After VATS segmentectomy and VATS lobectomy, minor complications occurred in 25.4 and $29.1 \%$ of patients, respectively, major complications in 7.1 and $8.4 \%$ of patients, and death in 0.8 and $0.4 \%$ of patients. Furthermore, the type of procedure was not associated with any specific complication, especially prolonged air leak, atelectasis or bronchopneumonia (Table 2). The results were similar when we analyzed complications in patients with lung cancer (data not shown).

The logistic regression model to construct the propensity score is shown in Additional file 1 and included gender, presence of COPD, histology, and location of the resection. The comparison of propensity score between interventions is shown in Additional file 2, with a favorable AUC of 0.744 (CI 95\% 0.706-0.782). According to this propensity score, we demonstrated that the occurrence of any complication or cardiopulmonary complication was similar between VATS segmentectomy and VATS lobectomy (Table 3).

\section{Risk factors}

The associations between patient characteristics and complications are shown in Additional file 3. The risk of complications increased significantly with age and then decreased in the oldest patients $(41.4 \%$ in patients between 70 and 79 years old and $25.4 \%$ in patients between 80 and 90 years old). Compared to those with a normal body mass index, underweight patients had an almost $10 \%$ increased risk of complication. However, overweight or obesity did not seem to impact the risk of complications. The occurrence of complications was significantly associated with ASA score $>2$, an increased number of pack years, presence of COPD, a decreased FEV1, and a decreased DLCO. The risk of complication also depended on the surgical indication, with a lower risk in patients with metastasis or benign lesion resection and a higher risk in patients with lung volume reduction surgery. However, while the size of the lesion differed between the two groups, size was unrelated to the occurrence of complications (mean $26.1 \pm 17.2$ without complication, $26.9 \pm 16.8$ with complication, $p=0.55$ ).

In the multivariate analysis, an ASA score above 2, and a FEV1 below $80 \%$ were significantly associated with the occurrence of complications (Table 4). However, 
Table 1 Correlations of patient characteristics with type of intervention by VATS

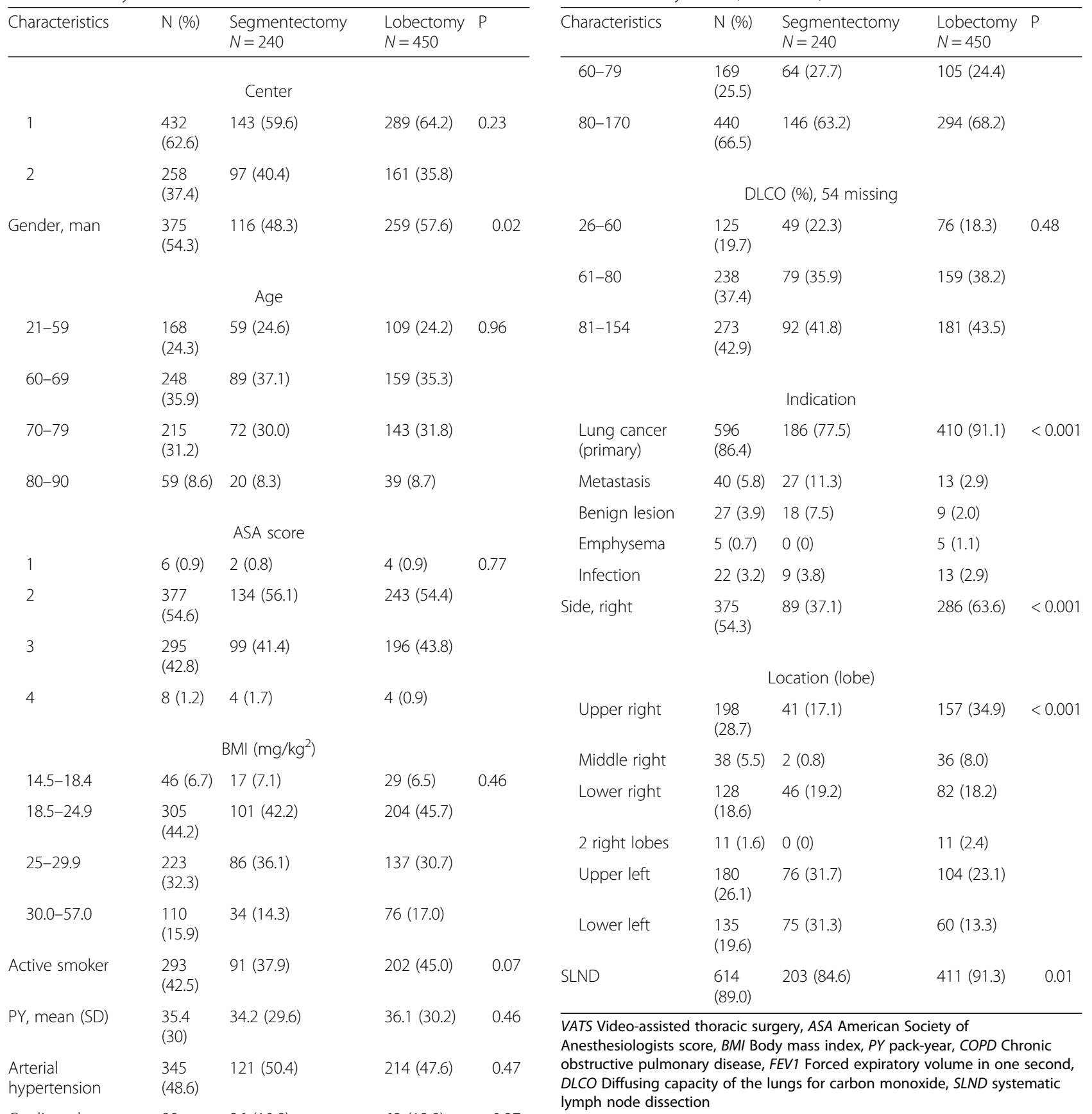

$\begin{array}{lllll}\text { Cardiopathy } & 88 & 26(10.8) & 62(13.8) & 0.27\end{array}$

$\begin{array}{lllll}\text { Diabetes } & 102 & 31(12.9) & 71(15.8) & 0.30\end{array}$

$\begin{array}{lllll}\text { COPD } & 259 & 99(41.3) & 160(35.6) & 0.14\end{array}$

$\begin{array}{lllll}\text { History of cancer } & 229 & 93(38.8) & 136(30.2) & 0.02\end{array}$

FEV1 (\%), 28 missing

24-59
Table 1 Correlations of patient characteristics with type of intervention by VATS (Continued)

\begin{tabular}{|c|c|c|c|c|}
\hline Characteristics & N (\%) & $\begin{array}{l}\text { Segmentectomy } \\
N=240\end{array}$ & $\begin{array}{l}\text { Lobectomy } \\
N=450\end{array}$ & $P$ \\
\hline $60-79$ & $\begin{array}{l}169 \\
(25.5)\end{array}$ & $64(27.7)$ & $105(24.4)$ & \\
\hline 80-170 & $\begin{array}{l}440 \\
(66.5)\end{array}$ & $146(63.2)$ & $294(68.2)$ & \\
\hline \multicolumn{5}{|c|}{ DLCO (\%), 54 missing } \\
\hline $26-60$ & $\begin{array}{l}125 \\
(19.7)\end{array}$ & $49(22.3)$ & $76(18.3)$ & 0.48 \\
\hline $61-80$ & $\begin{array}{l}238 \\
(37.4)\end{array}$ & 79 (35.9) & $159(38.2)$ & \\
\hline $81-154$ & $\begin{array}{l}273 \\
(42.9)\end{array}$ & $92(41.8)$ & 181 (43.5) & \\
\hline
\end{tabular}

$\begin{array}{lllll}\begin{array}{l}\text { Lung cancer } \\ \text { (primary) }\end{array} & 596 & 186(77.5) & 410(91.1) & <0.001 \\ \text { Metastasis } & 40(5.8) & 27(11.3) & 13(2.9) & \\ \text { Benign lesion } & 27(3.9) & 18(7.5) & 9(2.0) & \\ \text { Emphysema } & 5(0.7) & 0(0) & 5(1.1) & \\ \text { Infection } & 22(3.2) & 9(3.8) & 13(2.9) & \\ \text { Side, right } & 375 & 89(37.1) & 286(63.6) & <0.001 \\ & (54.3) & & & \end{array}$

\begin{tabular}{|c|c|c|c|c|}
\hline Upper right & $\begin{array}{l}198 \\
(28.7)\end{array}$ & $41(17.1)$ & 157 (34.9) & $<0.001$ \\
\hline Middle right & $38(5.5)$ & $2(0.8)$ & $36(8.0)$ & \\
\hline Lower right & $\begin{array}{l}128 \\
(18.6)\end{array}$ & $46(19.2)$ & $82(18.2)$ & \\
\hline 2 right lobes & $11(1.6)$ & $0(0)$ & $11(2.4)$ & \\
\hline Upper left & $\begin{array}{l}180 \\
(26.1)\end{array}$ & 76 (31.7) & $104(23.1)$ & \\
\hline Lower left & $\begin{array}{l}135 \\
(19.6)\end{array}$ & 75 (31.3) & $60(13.3)$ & \\
\hline LND & $\begin{array}{l}614 \\
(89.0)\end{array}$ & 203 (84.6) & $411(91.3)$ & 0.01 \\
\hline
\end{tabular}

benign nodule and metastasis resection, as well as middle lobe resection were significantly associated with a better postoperative outcome (Table 4). The ASA score and the FEV1 were not correlated with TMM grade.

\section{Length of hospital stay}

Segmentectomy by VATS was associated with a shorter duration of drainage than lobectomy by VATS ( 3 days, IQR [1-5] versus 2 days, IQR [1-3], respectively, $P=$ 
Table 2 Procedures and postoperative outcomes

\begin{tabular}{|c|c|c|c|}
\hline Outcomes & $\begin{array}{l}\text { Segmentectomy } \\
N=240\end{array}$ & $\begin{array}{l}\text { Lobectomy } \\
N=450\end{array}$ & $P$ \\
\hline $\begin{array}{l}\text { Patients with cardiopulmonary } \\
\text { complication, } \mathrm{N}(\%)\end{array}$ & $75(31.3)$ & $160(35.6)$ & 0.26 \\
\hline $\begin{array}{l}\text { Patients with any complication, } \\
N(\%)\end{array}$ & $80(33.3)$ & $171(38.0)$ & 0.22 \\
\hline $\begin{array}{l}\text { Complication per patient if } \\
\text { occurs, mean (SD) }\end{array}$ & $1.65(1.04)$ & $1.67(1.03)$ & 0.87 \\
\hline \multicolumn{4}{|c|}{ TMM, N (\%) } \\
\hline Grade 1-2 & $61(25.4)$ & $131(29.1)$ & 0.73 \\
\hline Grade 3-4 & $17(7.1)$ & $38(8.4)$ & \\
\hline Grade 5 & $2(0.8)$ & $2(0.4)$ & \\
\hline \multicolumn{4}{|l|}{ Type of complications, N (\%) } \\
\hline BPN & $30(12.5)$ & $67(14.9)$ & 0.42 \\
\hline PAL & $21(8.8)$ & $51(11.3)$ & 0.36 \\
\hline FA & $13(5.4)$ & $39(8.7)$ & 0.13 \\
\hline Pneumothorax & $16(6.7)$ & $21(4.7)$ & 0.29 \\
\hline Hemothorax & $3(1.2)$ & $9(2)$ & 0.56 \\
\hline ARDS & $4(1.7)$ & $4(0.9)$ & 0.46 \\
\hline Atelectasia & $5(2.1)$ & $14(3.1)$ & 0.63 \\
\hline Acute pulmonary edema & $1(0.4)$ & $1(0.2)$ & 1.0 \\
\hline $\begin{array}{l}\text { Massive subcutaneous } \\
\text { emphysema }\end{array}$ & $11(4.6)$ & $21(4.7)$ & 1.0 \\
\hline Chylothorax & $0(0)$ & $1(0.2)$ & 1.0 \\
\hline Pulmonary embolism & $2(0.8)$ & $1(0.2)$ & 0.28 \\
\hline BPF & $0(0)$ & $1(0.2)$ & 1.0 \\
\hline Empyema & $4(1.7)$ & $2(0.4)$ & 0.19 \\
\hline Cardiac infarction & $0(0)$ & $3(0.7)$ & 0.55 \\
\hline Recurrent nerve paralysis & $0(0)$ & $5(1.1)$ & 0.17 \\
\hline Acute renal failure & $5(2.1)$ & $17(3.8)$ & 0.26 \\
\hline Septic shock & $3(1.2)$ & $6(1.3)$ & 1.0 \\
\hline Cardiorespiratory arrest & $2(0.8)$ & $0(0)$ & 0.12 \\
\hline Ileus & $3(1.2)$ & $2(0.4)$ & 0.35 \\
\hline Upper Gl bleeding & $2(0.8)$ & $0(0)$ & 0.12 \\
\hline Gastroparesis & $1(0.4)$ & $0(0)$ & 0.35 \\
\hline Reoperation & $6(2.5)$ & $21(4.7)$ & 0.22 \\
\hline Duration of surgery, mean (SD) & $147.1(55.2)$ & $150.3(50.6)$ & 0.44 \\
\hline Conversion & $14(5.8)$ & $26(5.8)$ & 0.98 \\
\hline
\end{tabular}

Oncological histology, N (\%)

$\begin{array}{llll}\text { NSCLC } & 170(90.9) & 359(87.1) & 0.055 \\ \text { SCLC } & 2(1.1) & 7(1.7) & \\ \text { NET (AC, TC, LNEC) } & 15(8) & 33(8) & \\ \text { Other } & 0(0) & 13(3.2) & \\ \text { Tumor size (mm), mean (SD) } & 17.5(8.1) & 30.7(17.1) & < \\ & & & 0.001 \\ \text { Lymph node involvement } & N=183 & N=406 & 0.001\end{array}$

Table 2 Procedures and postoperative outcomes (Continued)

\begin{tabular}{clll}
\hline Outcomes & $\begin{array}{l}\text { Segmentectomy } \\
N=240\end{array}$ & $\begin{array}{l}\text { Lobectomy } \\
N=450\end{array}$ & $P$ \\
\hline pN1 & $6(3.3)$ & $39(9.6)$ & \\
pN2 & $10(5.5)$ & $47(11.6)$ & \\
Drainage duration, median [IQR] & $2[1-3]$ & $3[1-5]$ & 0.012 \\
LOS, median [IQR] & $6[4-9]$ & $7[5-11]$ & 0.045 \\
\hline
\end{tabular}

SD Standard deviation, NSCLC Non-small cell lung cancer, SCLC Small-cell lung cancer, NET Neuroendocrine tumor, TC Typical carcinoid, AC Atypical carcinoid, LNEC Large cell neuroendocrine carcinoma, LOS Length of hospital stay, TMM

Thoracic morbidity and mortality score, BPN Bronchopneumonia, PAL

Prolonged air leak, $A F$ Atrial fibrillation, ARDS Acute respiratory distress syndrome, BPF Bronchopulmonary fistula, Gl gastrointestinal

$0.011)$ and a shorter length of hospital stay (7 days, IQR [5-11] versus 6 days, IQR [4-9], respectively, $P=0.045$ ). The length of hospital stay (LOS) increased with the presence of complication $(6.1 \pm 3.5$ days versus $13.4 \pm 11$ days, $P<0.001)$. The LOS was also affected by TMM degree of complication, with an average of $12.3 \pm 8.4$ days for patients with minor complications and $17.2 \pm$ 16.3 days for patients with major complications $(P=$ 0.0034).

\section{Discussion}

Although complications after lobectomy have been characterized extensively, remarkably little is known about complications after anatomical resections by VATS. In this multicenter study, which compared complications between intentional segmentectomy and lobectomy by VATS, we have shown that: (i) the risk of complication after VATS segmentectomy was not significantly different than that after VATS lobectomy; (ii) the TMM scores were comparable between the two procedures; (iii) a FEV1 below $80 \%$ and an ASA score of $3-4$ were associated with an increased risk of complications (regardless of the procedure); (iv) benign nodule and metastasis resection, as well as middle lobe resection were associated with a better postoperative outcome; and (v) the drainage duration and the LOS were shorter in the VATS segmentectomy group.

In our study, we have shown that the rate, the type and the grade of complication were not different between segmentectomy and lobectomy by VATS. Neither the dissection of the intersegmental plane nor the parenchymal compression during segmentectomy seem to increase the risk of pulmonary complications. A few retrospective studies compared postoperative complication rate after VATS anatomical resections and found contradictory results [9-13]. Our finding of no difference between segmentectomy and lobectomy in incidence of cardiopulmonary complications contrasts with the findings of Deng et al. [9] This study shown a higher incidence of PAL and pulmonary complications after VATS segmentectomy. 
Table 3 Logistic regression models for the occurrence of any complication, and of a cardiopulmonary complication

\begin{tabular}{|c|c|c|c|c|c|}
\hline \multicolumn{2}{|c|}{ Models } & \multicolumn{2}{|l|}{ Any complication } & \multicolumn{2}{|c|}{ Cardiopulmonary complication } \\
\hline & & $\mathrm{OR}(95 \% \mathrm{Cl})$ & $\mathrm{P}$ & OR $(95 \% \mathrm{Cl})$ & $\mathrm{P}$ \\
\hline \multirow[t]{2}{*}{1} & VATS segmentectomy ${ }^{a}$ & $0.91(0.61-1.30)$ & 0.58 & $0.93(0.65-1.34)$ & 0.71 \\
\hline & Propensity score $^{b}$ & $0.42(0.16-1.17)$ & 0.10 & $0.46(0.19-1.13)$ & 0.049 \\
\hline 2 & VATS segmentectomy ${ }^{a}$ & $0.93(0.70-1.24)$ & 0.62 & $0.86(0.60-1.24)$ & 0.41 \\
\hline
\end{tabular}

Model 1: standard logistic regression, where the propensity score was left as a continuous probability between 0 and 1. Model 2: Conditional logistic regression, with 15 sets matched for propensity $(0.100-0.149,0.150-0.199,0.200-0.249$, etc). Fifty-five patients with a propensity for segmentectomy $<0.10$ and $>0.85$ were excluded, as all were treated with the same intervention. ${ }^{a}$ vs lobectomy ${ }^{b}$ probability of 1 vs 0

VATS Video-assisted thoracic surgery, OR Odds ratio, $\mathrm{Cl}$ Confidence interval

Because of their small sample size in the segmentectomy group $(N=35)$, the authors suggested that a learning curve could explain this result. In their comparison of postoperative complications between segmentectomy ( $N=39)$ and lobectomy $(N=81)$, Zhong et al. [12] found that despite the small sample size, postoperative complication rates were low and similar $(12.8 \%$ vs. $12.3 \%, P=0.94)$ and the most frequent complication was atrial fibrillation ( $2.6 \%$ vs. $3.7 \%$ ). However, the patients had few comorbidities and only $18.9 \%$ of patients suffered from COPD. A study by Whang et al. [11] that included only pulmonary complications in a match-paired study of 94 segmentectomies and 94 lobectomies reported comparable postoperative pulmonary complication rates of $10.6 \%$ for segmentectomies and $17.2 \%$ for lobectomies $(P=0.1)$; $18 \%$ of patients suffered from COPD. Recently, Song et al.

Table 4 Multivariate model of risk factors for complications (intervention type was forced into the model)

\begin{tabular}{|c|c|c|}
\hline Risk factors & OR $(95 \% \mathrm{Cl})$ & $P$ \\
\hline Segmentectomy (vs lobectomy) by VATS & $0.89(0.62-1.28)$ & 0.74 \\
\hline Center 2 (vs Center 1) & $0.71(0.50-1.01)$ & 0.051 \\
\hline ASA 3-4 (vs 1-2) & $1.55(1.10-2.19)$ & 0.011 \\
\hline FEV1 < 80\% (vs $\geq 80 \%)$ & $1.61(1.11-2.30)$ & 0.009 \\
\hline Indication & & 0.042 \\
\hline Lung cancer (primary) & 1 (reference) & - \\
\hline Metastasis & $0.32(0.13-0.80)$ & 0.015 \\
\hline Benign lesion & $0.27(0.08-0.95)$ & 0.042 \\
\hline Emphysema & $1.33(0.21-8.31)$ & 0.76 \\
\hline Infection & $0.74(0.22-2.44)$ & 0.64 \\
\hline Location (lobe) & & 0.066 \\
\hline Upper (right or left) & 1 (reference) & - \\
\hline Middle right & $0.32(0.13-0.82)$ & 0.018 \\
\hline Lower (right or left) & $0.96(0.68-1.36)$ & 0.82 \\
\hline 2 right lobes & $2.15(0.58-8.01)$ & 0.25 \\
\hline
\end{tabular}

OR Odds ratio, $\mathrm{Cl}$ Confidence interval, VATS Video-assisted thoracic surgery, ASA American Society of Anesthesiologists score, FEV1 Forced expiratory volume in one second reported similar rates of postoperative pulmonary complications $(15.3 \%)$ between segmentectomy $(N=41)$ and lobectomy $(N=122)$ [10]. Finally, Lin et al. compared segmentectomy $(N=32)$ and lobectomy $(N=47)$ by a single-port approach, finding no difference in the postoperative complication rate $(P=0.19)$ [13].

Although these studies showed similar results to our findings, their complication rates appeared lower. However, they included only patients with early-stage NSCLC and reported only cardio-pulmonary complications. One explanation for the higher rate of complications in our study is that we included all types of complications. We report postoperative complications routinely and extensively, which could increase the number of complications $[17,18]$. In addition, the higher rate of patient comorbidities in our study, as compared to some other studies, could increase the rate of complication, as established in the European risk models for morbidity (Eurolung1) score [19]. In this sense, Deng et al. reported a higher rate of complications after VATS segmentectomy and lobectomy ( $68.6 \%$ vs. $74.1 \%)$, with a comorbidity rate comparable to our findings. Finally, our higher incidence of pneumonia in particular could be explained by the higher rate of comorbidities and patients with COPD.

In our study, predictive factors for complications include an ASA score $>2$ and a FEV $1<80 \%$ of the predicted value, regardless of the procedure. However, the ASA score and the FEV1 were not associated with the TMM grade. The ASA score as a predictive factor for complication was previously established in the Eurolung 1 score [19]. In thoracotomy patients, FEV1 $<60 \%$ has been associated with a higher rate of pulmonary complications [20, 21]. We also found that FEV1 $<60 \%$ was a predictive factor of post-operative complications in anatomical resection by VATS. As compared to an FEV1 above $80 \%$, the risk of complication increased by $60 \%$ in patients with an FEV1 under $60 \%$ of the predicted value. Contrary to FEV1, a lower DLCO is not associated with an increased risk of complication. Similarly to our findings, Benattia et al. showed that the FEV1, but not DLCO, independently predicted 
postoperative outcome in VATS anatomical resection [22]. However, another study did not report FEV1 and DLCO as independent predictor factors for pulmonary complications after lobectomy by VATS [23]. According to our results, probably that preoperative risk assessment recommended by the ERS/ESTS task force to predict postoperative morbidity after resection by thoracotomy could be used for all anatomical resections by VATS. However, further studies are needed to confirm this hypothesis.

The postoperative complications after anatomical resection for other indications than NSCLC have not been studied yet. In our study, resection of metastasis and benign lesion are associated with a lower risk of postoperative complication, regardless of the type of resection. A less extensive dissection during intervention in these indications could explain our results.

Interestingly, the drainage duration and the LOS was shorter in VATS segmentectomy than in VATS lobectomy. Furthermore, VATS segmentectomy showed a similar rate of conversion as VATS lobectomy and could be considered safe. Further studies are needed to compare the global costs between the two procedures.

Our study had several limitations. First, it was a retrospective analysis of two centers experience in VATS segmentectomy and lobectomy and may introduce selection and information bias. Second, the low granularity of data regarding the management of complications allowed only a rough classification of the TMM grade. Third, post-operative management was based on local practice, which differed between the two centers, although both had similar proportions of VATS segmentectomies and VATS lobectomies. Fourth, data about VATS segmentectomies included the learning phase of the technique, which could have influenced the postoperative outcomes during the initial phase. We have not analyzed the difference in complication rates among the study periods. Fifth, as expected with registered data, several factors were missing from our data sets, including the 90-day mortality and comorbidity scores. For these reasons, the EuroLung1 EuroLung2 scores could not be used [19]. Sixth, perioperative data was lacking regarding the complexity of the procedure and perioperative complications. However, the large number of patients with VATS segmentectomy available for analysis, and the high granularity of data collected regarding complications are major strengths of this study. Finally, another limitation is that if the choice of treatment modality (segmentectomy vs lobectomy) was driven by unmeasured patient characteristics that are associated with the risk of complication, substantial residual confounding would presist (confounding by indication). Only a randomized trial comparing the two techniques would eliminate this potential problem.

\section{Conclusions}

In conclusion, we did not observe significant differences in terms of postoperative complications between intentional VATS segmentectomies and lobectomies, even after adjustment for differences in patient characteristics. Both approaches seem to yield similar rates of complications and the occurrence of complications depends on the ASA score and the percentage of the predicted FEV1.

\section{Supplementary information}

Supplementary information accompanies this paper at https://doi.org/10 1186/s13019-019-1021-9.

Additional file 1. Multivariate logistic regression models to predict segmentectomy by VATS (versus lobectomy by VATS) VATS: Videoassisted thoracic surgery, OR: Odds ratio, Cl: Confidence interval, COPD: Chronic obstructive pulmonary disease.

Additional file 2. Comparison of propensity score according to type of intervention by VATS VATS: Video-assisted thoracic surgery, SD: Standard deviation, AUC: Area under the curve, $\mathrm{Cl}$ : Confidence interval.

Additional file 3. Associations of patient characteristics with complications. VATS: Video-assisted thoracic surgery, ASA: American Society of Anesthesiologists Score, BMI: Body mass index, PY: pack-years, COPD: Chronic obstructive pulmonary disease, FEV1: Forced expiratory volume in one second, DLCO: Diffusing capacity of the lungs for carbon monoxide, SLND: systematic lymph node dissection.

\section{Abbreviations}

ARDS: Acute respiratory distress syndrome; ASA: American Society of Anesthesiologists; BPN: Bronchopneumonia; COPD: chronic obstructive pulmonary disease; DLCO: Diffusing capacity of the lungs for carbon monoxide; FEV1: Forced expiratory volume in one second; LOS: Length of hospital stay; NSCLC: non-small cell lung lancer; PAL: Prolonged air leak; PY: pack-year; TMM: Thoracic morbidity and mortality score; VATS: videoassisted thoracic surgery

\section{Acknowledgements}

We especially thank Pamela Derish for her review of the article and her help.

\section{Authors' contributions}

BB designed the study, recorded data, analyzed and interpreted the data, wrote the manuscript. EAB recorded data, interpreted the data, read, substantively revised and approved the final manuscript. TP analyzed the data interpreted the data, read, substantively revised and approved the final manuscript. MJL read, substantively revised and approved the final manuscript. AS recorded data, read, substantively revised and approved the final manuscript. MK recorded data, read, substantively revised and approved the final manuscript. JYP read, substantively revised and approved the final manuscript. TK read, substantively revised and approved the final manuscript. FT interpreted the data, read, substantively revised and approved the final manuscript. WK interpreted the data, read, substantively revised and approved the final manuscript. MG designed the work, recorded data, interpreted the data, read, substantively revised and approved the final manuscript. Co-authors have agreed both to be personally accountable for the author's own contributions and to ensure that questions related to the accuracy or integrity of any part of the work, even ones in which the author was not personally involved, are appropriately investigated, resolved, and the resolution documented in the literature. All authors read and approved the final manuscript.

\section{Funding}

No funding.

\section{Availability of data and materials}

The datasets used and/or analysed during the current study are available from the corresponding author on reasonable request. 


\section{Ethics approval and consent to participate}

The local ethics committee approved this study (referral number: 201800179) and waived the need to obtain informed patient consent.

\section{Consent for publication}

Not applicable

\section{Competing interests}

The authors declare that they have no competing interests.

\section{Author details}

'Division of Thoracic and Endocrine Surgery, University Hospitals of Geneva, Geneva, Switzerland. ${ }^{2}$ Division of Thoracic Surgery, Centre Hospitalier Universitaire Vaudois, Lausanne, Switzerland. ${ }^{3}$ Division of Clinical Epidemiology, University Hospitals of Geneva, Geneva, Switzerland. ${ }^{4}$ Division of Anesthesiology, University Hospitals of Geneva, Geneva, Switzerland.

Received: 11 September 2019 Accepted: 28 October 2019

Published online: 07 November 2019

\section{References}

1. Zhang Z, Zhang Y, Feng H, Yao Z, Teng J, Wei D, et al. Is video-assisted thoracic surgery lobectomy better than thoracotomy for early-stage nonsmall-cell lung cancer? A systematic review and meta-analysis. Eur J Cardiothorac Surg. 2013;44

2. Al-Ameri M, Bergman P, Franco-Cereceda A, Sartipy U. Video-assisted thoracoscopic versus open thoracotomy lobectomy: a Swedish nationwide cohort study. J Thorac Dis. 2018 Jun;10(6):3499.

3. Yan TD, Black D, Bannon PG, McCaughan BC. Systematic review and metaanalysis of randomized and nonrandomized trials on safety and efficacy of video-assisted thoracic surgery lobectomy for early-stage non-small-cell lung cancer. J Clin Oncol. 2009;27.

4. Bendixen M, Jørgensen OD, Kronborg C, Andersen C, Licht PB. Postoperative pain and quality of life after lobectomy via video-assisted thoracoscopic surgery or anterolateral thoracotomy for early stage lung cancer: a randomised controlled trial. Lancet Oncol. 2016 Jun;17(6):836.

5. Cao C, Chandrakumar D, Gupta S, Yan TD, Tian DH. Could less be more?-a systematic review and meta-analysis of sublobar resections versus lobectomy for non-small cell lung cancer according to patient selection. Lung Cancer. 2015;89:121.

6. Liu Q, Wang H, Zhou D, Deng X, Min J, Dai J. Comparison of clinical outcomes after thoracoscopic sublobectomy versus lobectomy for stage I nonsmall cell lung cancer: a meta-analysis. J Cancer Res Ther. 2016;12.

7. Charloux A, Quoix E. Lung segmentectomy: does it offer a real functional benefit over lobectomy? Eur Respir Rev. 2017;25, 26(146). https://doi.org/10. 1183/16000617.0079-2017.

8. Nomori H, Shiraishi A, Cong Y, Sugimura H, Mishima S. Differences in postoperative changes in pulmonary functions following segmentectomy compared with lobectomy. Eur J Cardiothorac Surg 2018 1;53(3):640.

9. Deng B, Cassivi SD, de Andrade M, Nichols FC, Trastek VF, Wang Y, et al. Clinical outcomes and changes in lung function after segmentectomy versus lobectomy for lung cancer cases. I Thorac Cardiovasc Surg. 2014:148:1186.

10. Song CY, Sakai T, Kimura D, Tsushima T, Fukuda I. Comparison of perioperative and oncological outcomes between video-assisted segmentectomy and lobectomy for patients with clinical stage IA non-small cell lung cancer: a propensity score matching study. J Thorac Dis. 2018; 10(8):4891.

11. Hwang Y, Kang CH, Kim HS, Jeon JH, Park IK, Kim YT. Comparison of thoracoscopic segmentectomy and thoracoscopic lobectomy on the patients with non-small cell lung cancer: a propensity score matching study. Eur J Cardiothorac Surg. 2015 Aug;48(2):273.

12. Zhong C, Fang W, Mao T, Yao F, Chen W, Hu D. Comparison of thoracoscopic segmentectomy and thoracoscopic lobectomy for small-sized stage IA lung cancer. Ann Thorac Surg. 2012;94(2):362.

13. Lin Y, Zheng W, Zhu Y, Guo Z, Zheng B, Chen C. Comparison of treatment outcomes between single-port video-assisted thoracoscopic anatomic segmentectomy and lobectomy for non-small cell lung cancer of earlystage: a retrospective observational study. J Thorac Dis. 2016 Jun;8(6):1290.
14. ARDS Definition Task Force, Ranieri VM, Rubenfeld GD, Thompson BT, Ferguson ND, Caldwell E, et al. Acute respiratory distress syndrome: the Berlin Definition. JAMA. 2012 Jun 20;307(23):2526.

15. Seely AJE, Ivanovic J, Threader J, Al-Hussaini A, Al-Shehab D, Ramsay T, et al. Systematic classification of morbidity and mortality after thoracic surgery. Ann Thorac Surg. 2010;90:936.

16. Brunelli A, Charloux A, Bolliger CT, Rocco G, Sculier JP, Varela G, et al. ERS/ ESTS clinical guidelines on fitness for radical therapy in lung cancer patients (surgery and chemo-radiotherapy). Eur Respir J. 2009 Jul;34(1):17.

17. Licker M, Karenovics W, Diaper J, Frésard I, Triponez F, Ellenberger C, et al. Short-Term Preoperative High-Intensity Interval Training in Patients Awaiting Lung Cancer Surgery: A Randomized Controlled Trial. J Thorac Oncol. 2017 Feb;12(2):323.

18. Ellenberger C, Garofano N, Reynaud T, Triponez F, Diaper J, Bridevaux PO, et al. Patient and procedural features predicting early and mid-term outcome after radical surgery for non-small cell lung cancer. J Thorac Dis. 2018;10(11):6020-9.

19. Brunelli A, Salati M, Rocco G, Varela G, Van Raemdonck D, Decaluwe H, et al. European risk models for morbidity (EuroLung1) and mortality (EuroLung2) to predict outcome following anatomic lung resections: an analysis from the European Society of Thoracic Surgeons database. Eur J Cardiothorac Surg 2017 1:51(3):490.

20. Licker MJ, Widikker I, Robert J, Frey JG, Spiliopoulos A, Ellenberger C, et al. Operative mortality and respiratory complications after lung resection for cancer: impact of chronic obstructive pulmonary disease and time trends. Ann Thorac Surg. 2006:81:1830-7. https://doi.org/10. 1016/j.athoracsur.2005.11.048.

21. Salati M, Brunelli A. Risk Stratification in Lung Resection. Curr Surg Rep. 2016;4(11):37.

22. Benattia A, Debeaumont D, Guyader V, Tardif C, Peillon C, Cuvelier A, et al. Physiologic assessment before video thoracoscopic resection for lung cancer in patients with abnormal pulmonary function. J Thorac Dis. 2016; 8(6):1170-8.

23. Berry MF, Villamizar-Ortiz NR, Tong BC, Burfeind WR Jr, Harpole DH, D'Amico TA, et al. Pulmonary function tests do not predict pulmonary complications after thoracoscopic lobectomy. Ann Thorac Surg. 2010;89.

\section{Publisher's Note}

Springer Nature remains neutral with regard to jurisdictional claims in published maps and institutional affiliations.

Ready to submit your research? Choose BMC and benefit from:

- fast, convenient online submission

- thorough peer review by experienced researchers in your field

- rapid publication on acceptance

- support for research data, including large and complex data types

- gold Open Access which fosters wider collaboration and increased citations

- maximum visibility for your research: over $100 \mathrm{M}$ website views per year

At BMC, research is always in progress.

Learn more biomedcentral.com/submissions 